\title{
Modeling of Dielectric Relaxation for Lossy Materials at Microwave Frequencies using Polynomial Approaches
}

\author{
K. Y. You ${ }^{a^{*}}$, Z. Abbas ${ }^{\text {b }}$, M. F. A. Malek ${ }^{\text {c }}$ E. M. Cheng ${ }^{c}$ \& H. K. Mun ${ }^{a}$ \\ ${ }^{a}$ Faculty of Electrical Engineering, Universiti Teknologi Malaysia, 81310 UTM Johor Bahru \\ ${ }^{b}$ Faculty of Science, Universiti Putra Malaysia, 43400 UPM Serdang, Selangor \\ 'Universiti Malaysia Perlis, 02600, UNIMAP Perlis \\ *Corresponding author: kyyou@fke.utm.my
}

\section{Article history}

Received: 8 March 2012

Received in revised form: 10 April

2012

Accepted: 18 July 2012

Graphical abstract

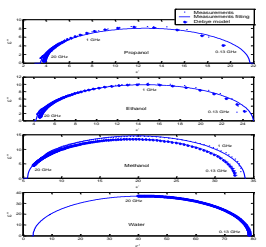

\section{Abstract}

This paper reviews the dielectric modeling techniques and features of various dielectric models. In fact, many of the dielectric models have a polynomial characteristic, thus polynomial fitting is proposed in order to estimate the parameters in the dielectric model based on measured data. The coefficients of the polynomial equation were optimized with the measured data using HP 85070 B dielectric probe. Finally, the parameters in the dielectric models can be easily determined, based on the estimated polynomial coefficients. The parameters of the dielectric model were successfully estimated and compared with parameter values in the literature.

Keywords: Relative permittivity; dielectric model; polynomial approaches

(c) 2012 Penerbit UTM Press. All rights reserved.

\subsection{INTRODUCTION}

Dielectric study is important for materials located in the electric field at microwave frequencies, since at microwave frequencies the polar molecules in some dielectric materials become excited. In the industry field, the study of dielectric properties of industrial materials is becoming increasingly critical. This is because the dielectric properties of materials has played an important role in the construction of high- frequency electronic components, the quality of printed circuit board (PCB) substrate, the efficiency of microwave absorption materials, and the performance of dielectric antenna design.

The interaction between dielectric materials with electromagnetic fields can be best described by complex dielectric permittivity, $\varepsilon_{r}=\varepsilon_{r}^{\prime}-j \varepsilon_{r}^{\prime \prime}$. The real part, $\varepsilon_{r}^{\prime}$ is the dielectric constant which is the parameter influencing the electric field distribution and the phase of waves traveling through the material. In contrast, the imaginary part, the socalled loss factor, $\varepsilon_{r}^{\prime \prime}$ influences the energy absorption or attenuation of the material. Dielectric spectroscopy is a macroscopic study requiring theoretical formulations to represent and describe the dielectric mechanism inside the materials.

The first dielectric expression was derived by Debye [6] based on permanent dipole moments in dielectric materials. However, the polarization molecules in inhomogeneous insulator materials are complex due to many body interactions between binding molecules. Thus, a lot of the dielectric equation was modified from the ideal Debye theory, such as Cole-Cole (CC) [4], Davidson-Cole (DC) [5], and Havriliak-Negami (HN) [9], as well as Kohlrausch-Williams-Watts (KWW) distribution function, in order to represent the actual properties of the material. Those models are more suitable for lossy materials at microwave frequency range (molecules orientational polarization frequency). Normally, the ideal Debye's model [6] involves a search for the three parameters $\left(\varepsilon_{s}, \varepsilon_{\infty}\right.$ and $\tau$ ) as detailed in Section 2 and 3. In order to obtain a calculated value of permittivity closed to the measurement results, some empirical parameter were added to the model to establish a good fit with the measurement data, such as the modified Cole-Cole model [4]. In this study, the polynomial approaches are used to establish the parameters inside the dielectric models based on the measurement results.

\subsection{DIELECTRIC MODELS}

In general cases, after the dielectric material has been placed in a steady external field, its molecules tend to gravitate exponentially to an equilibrium state as given by [14].

$$
f(t)=\exp (-t / \tau)
$$


The relaxation function, $f(t)$ can be related to relative permittivity, $\varepsilon_{r}$ material via Laplace transform as

$$
\frac{\varepsilon_{r}-\varepsilon_{\infty}}{\varepsilon_{s}-\varepsilon_{\infty}}=\int_{0}^{\infty}\left[-\frac{\partial}{\partial t} f(t)\right] e^{-j \omega t} d t
$$

Thus, in the frequency domain, ideal relative permittivity can be expressed as equation (3) (in Table 1). However, various alternative expression were done to fit the practical permittivity data, such as the Cole-Cole model [4], the Davidson-Cole model [5], and the Havriliak-Negami model [9], as listed in Table 1.

Table 1 Various frequency-domain dielectric models

\begin{tabular}{|c|c|}
\hline & Frequency-Domain Formulations \\
\hline $\begin{array}{l}\text { Debye's } \\
\text { Model [6] }\end{array}$ & $\begin{array}{l}\varepsilon_{r}=\varepsilon_{\infty}+\frac{\varepsilon_{s}-\varepsilon_{\infty}}{1+j \omega \tau} \\
\text { where } \varepsilon_{\infty} \text { and } \varepsilon_{s} \text { are the optical permittivity and } \\
\text { static permittivity, respectively. Symbol } \omega \text { and } \tau \\
\text { are the angular frequency and relaxation time. }\end{array}$ \\
\hline $\begin{array}{l}\text { Cole-Cole } \\
\text { Model [4] }\end{array}$ & $\begin{array}{c}\qquad \varepsilon_{r}=\varepsilon_{\infty}+\frac{\varepsilon_{s}-\varepsilon_{\infty}}{1+(j \omega \tau)^{\alpha}} \\
\text { where } \alpha \text { is the empirical constant with } 0<\alpha \leq 1 .\end{array}$ \\
\hline $\begin{array}{l}\text { Cole- } \\
\text { Davidson } \\
\text { Model [5] }\end{array}$ & $\begin{array}{c}\qquad \varepsilon_{r}=\varepsilon_{\infty}+\frac{\varepsilon_{s}-\varepsilon_{\infty}}{(1+j \omega \tau)^{\beta}} \\
\text { (5) } \\
\text { where } \beta \text { is the empirical constant with } 0<\beta \leq 1 .\end{array}$ \\
\hline $\begin{array}{l}\text { Havriliak } \\
\& \text { Negami } \\
\text { Model [9] }\end{array}$ & $\begin{array}{l}\varepsilon_{r}=\varepsilon_{\infty}+\frac{\varepsilon_{s}-\varepsilon_{\infty}}{\left[1+(j \omega \tau)^{\alpha}\right]^{\beta}} \\
\text { (6) } \\
\text { where } \beta \text { and } \alpha \text { are the empirical constant with } 0<\beta \leq 1 \\
\text { and } 0<\alpha \leq 1 .\end{array}$ \\
\hline
\end{tabular}

In practice, in a large number of heterogeneous systems it is found that the polarization does not decay as equation (1), but it is a response as a stretched exponential function [1].

$$
f(t)=\exp (-t / \tau)^{\gamma}
$$

The stretched exponential behavior is called KohlrauschWilliams-Watts (KWW). By using equation (7) as a decay function, equation (2) in the time-domain becomes

$$
\varepsilon_{r}=\varepsilon_{\infty}+\frac{\left(\varepsilon_{s}-\varepsilon_{\infty}\right) \gamma}{\tau^{\gamma}} \int_{0}^{\infty} t^{\gamma-1} f(t) e^{-j \omega t} d t
$$

For $(N+1)$ relaxation systems, the dielectric properties can be represented by

$$
\varepsilon_{r}=\varepsilon_{\infty}+\frac{\varepsilon_{s}-\varepsilon_{1}}{1+j \omega \tau_{1}}+\sum_{n=1}^{N} \frac{\varepsilon_{n}-\varepsilon_{n+1}}{1+j \omega \tau_{n+1}}
$$

\subsection{DIELECTRIC MODELS IN POLYNOMIAL EXPRESSIONS}

The approximated series of the Debye model provides more degrees of freedom to specify the broadness of experimental relaxation peaks. The polynomial equations listed in Table 2 are used to determine the dielectric parameters $\varepsilon_{s}, \varepsilon_{\infty}$, and $\tau$.

As mentioned in Section 2, the relative complex permittivity, $\varepsilon_{r}$ for materials with only a single relaxation frequency is best described by the Debye or Cole-Cole model. The three widely acceptable representations $[4,13]$ of the Debye and Cole-Cole model are:

1) Cole-Cole plot, equation (12) or (13)

2) $\quad \varepsilon_{r}^{\prime}$ versus $-\omega \varepsilon_{r}^{\prime \prime}$ plot equation (10) and

$\varepsilon_{r}^{\prime}$ versus $\varepsilon_{r}^{\prime \prime} / \omega$ plot, equation (11)

Series expansion of Equation (3) is usually used for c polynomial fitting of experimental data from which $\varepsilon_{s}$ and $\varepsilon_{\infty}$ can be estimated easily, once the relaxation time, $\tau$ is known. The series expansion is described in detail in the Appendix. The real part of (3) can be represented in terms of equation (15). Since heterogeneous mixtures or materials may provide various forms of dispersion, relaxation time, $\tau$, can thus (3) be written in the form of equation (17). Similarly, the imaginary part of (3) can be represented in the form of equation (18).

The natural domain of the KWW relaxation function is time domain. In this study, the KWW relaxation function is transformed to frequency domain by expanding the function as a series expression given as equation (19) and (20). This series is only suitable when implemented at low frequencies, as well as short relaxation time, $\tau$. This is because the higher series terms in (19) and (20) are weak when the series values are greater than the calculation limit of the software.

The corresponding values of the empirical parameters between the Kohlrausch-Williams-Watts (KWW) function in time domain and the Havriliak-Negami (HN) functions in the frequency domain were found using numerical simulations by Alvarez et al. (1991). The corresponding value of those parameters, obtained from the literature [1] was plotted in Figure 1. In this work, the relationship between those parameters was re-expressed in polynomial form as tabulated in Table 3. 

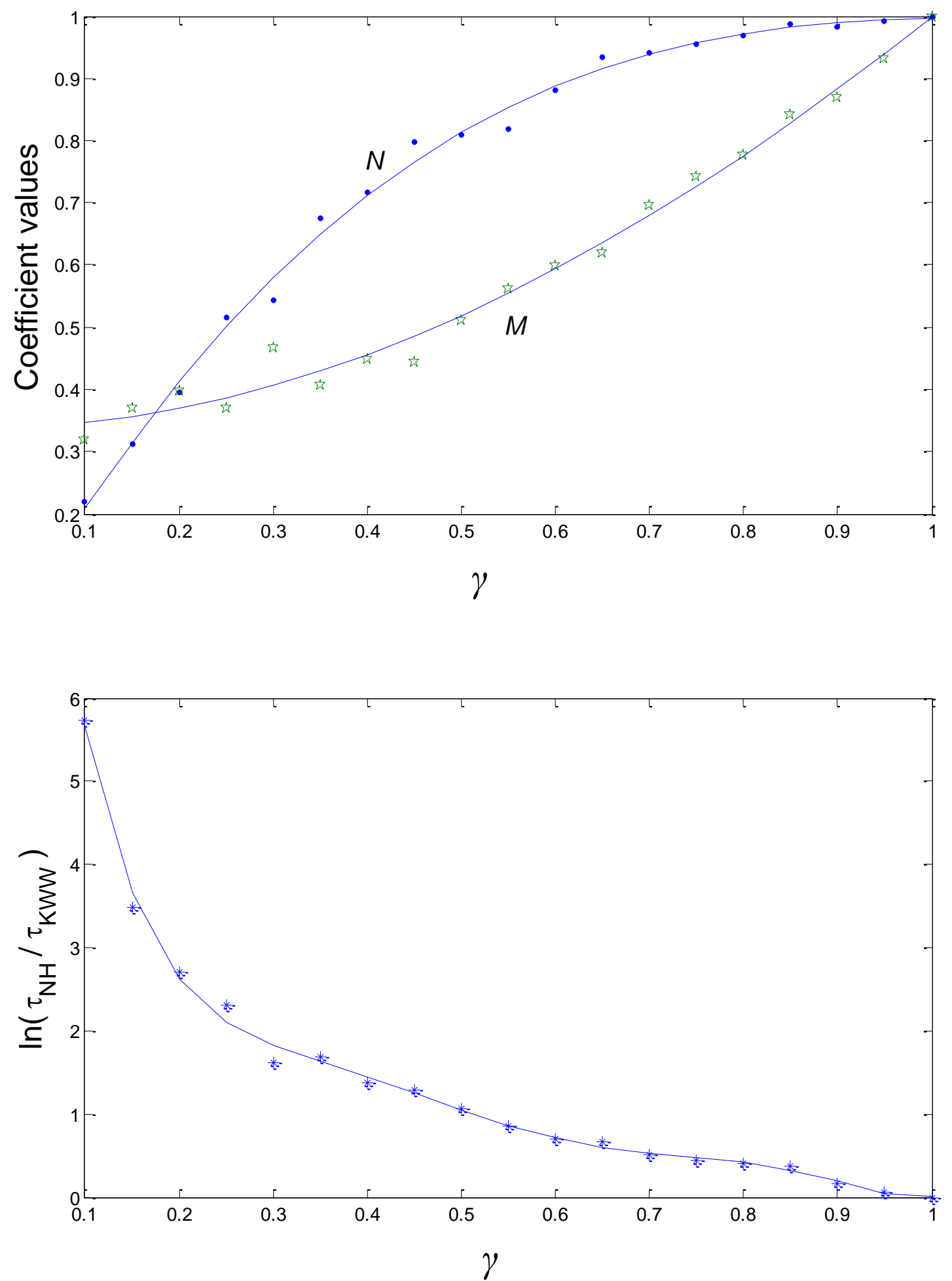

Figure 1 Values of the Havriliak-Negami (HN) fitting parameters as functions ofthe corresponding $\gamma$ values. The solid line is polynomial fitting and the equations are tabulated in Table 3 
Table 2 Various of frequency-domain dielectric models

\begin{tabular}{|c|c|}
\hline Polynomial Expressions & Dielectric Expressions \\
\hline $\begin{array}{l}\text { Linear equation } \\
y=m x+c\end{array}$ & $\begin{array}{l}\text { Debye characteristics } \\
\varepsilon_{r}^{\prime}=-\left(\omega \varepsilon_{r}^{\prime \prime}\right) \tau+\varepsilon_{s} \\
\varepsilon_{r}^{\prime}=\left(\varepsilon^{\prime \prime} / \omega \tau\right)+\varepsilon_{\infty}\end{array}$ \\
\hline \multirow[t]{2}{*}{$\begin{array}{l}\text { Quadratic equation } \\
y=a x^{2}+b x+c\end{array}$} & $\begin{array}{l}\text { Debye characteristics } \\
\left(\varepsilon_{r}^{\prime \prime}\right)^{2}=-\left(\varepsilon_{r}^{\prime}\right)^{2}+\left(\varepsilon_{s}+\varepsilon_{\infty}\right) \varepsilon_{r}^{\prime}-\varepsilon_{s} \varepsilon_{\infty}\end{array}$ \\
\hline & $\begin{array}{l}\text { Cole-Cole characteristics } \\
P_{1}\left(\varepsilon_{r}^{\prime \prime}\right)^{2}=-\left(\varepsilon_{r}^{\prime}\right)^{2}+\left(\varepsilon_{s}+\varepsilon_{\infty}\right) \varepsilon_{r}^{\prime}-P_{2}+P_{3} \\
\text { where } \\
P_{1}=\left[2 \tan \left(\frac{(1-N) \pi}{2}\right)+1\right] \\
P_{2}=\frac{1}{4}\left[\left(\varepsilon_{s}+\varepsilon_{\infty}\right)^{2}+\left(\varepsilon_{s}-\varepsilon_{\infty}\right)^{2} \tan ^{2}\left(\frac{(1-N) \pi}{2}\right)\right] \\
(14 \mathrm{~b}) \\
P_{3}=\frac{1}{4}\left(\varepsilon_{s}-\varepsilon_{\infty}\right)^{2} \sec ^{2}\left(\frac{(1-N) \pi}{2}\right)\end{array}$ \\
\hline \multirow[t]{2}{*}{$\begin{array}{l}N \text {-order polynomial equation } \\
y=\sum_{n=0}^{N} a_{n} x^{n}\end{array}$} & $\begin{array}{l}\text { Debye characteristics (Single relaxation) } \\
\text { Real Part } \\
\varepsilon_{r}^{\prime} \approx \varepsilon_{s}-A_{1} x+A_{2} x^{2}-A_{3} x^{3}+A_{4} x^{4}-\ldots \\
\text { where } x=f^{2} \text { and } \\
A_{1}=(2 \pi \tau)^{2}\left(\varepsilon_{s}-\varepsilon_{\infty}\right) \quad ; \quad A_{2}=(2 \pi \tau)^{4}\left(\varepsilon_{s}-\varepsilon_{\infty}\right) \\
A_{3}=(2 \pi \tau)^{6}\left(\varepsilon_{s}-\varepsilon_{\infty}\right) ; \quad A_{4}=(2 \pi \tau)^{8}\left(\varepsilon_{s}-\varepsilon_{\infty}\right) \cdots\end{array}$ \\
\hline & $\begin{array}{l}\begin{array}{l}\text { Imaginary Part } \\
\frac{\varepsilon_{r}^{\prime \prime}}{f} \approx B_{1}-B_{2} x+B_{3} x^{2}-B_{4} x^{3}+B_{5} x^{4}-\ldots \\
\text { where } x=f^{2} \text { and } \\
B_{1}=(2 \pi \tau)\left(\varepsilon_{s}-\varepsilon_{\infty}\right) \quad ; \quad B_{2}=(2 \pi \tau)^{3}\left(\varepsilon_{s}-\varepsilon_{\infty}\right) \\
B_{3}=(2 \pi \tau)^{5}\left(\varepsilon_{s}-\varepsilon_{\infty}\right) ; \quad B_{4}=(2 \pi \tau)^{7}\left(\varepsilon_{s}-\varepsilon_{\infty}\right) \cdots\end{array}\end{array}$ \\
\hline
\end{tabular}




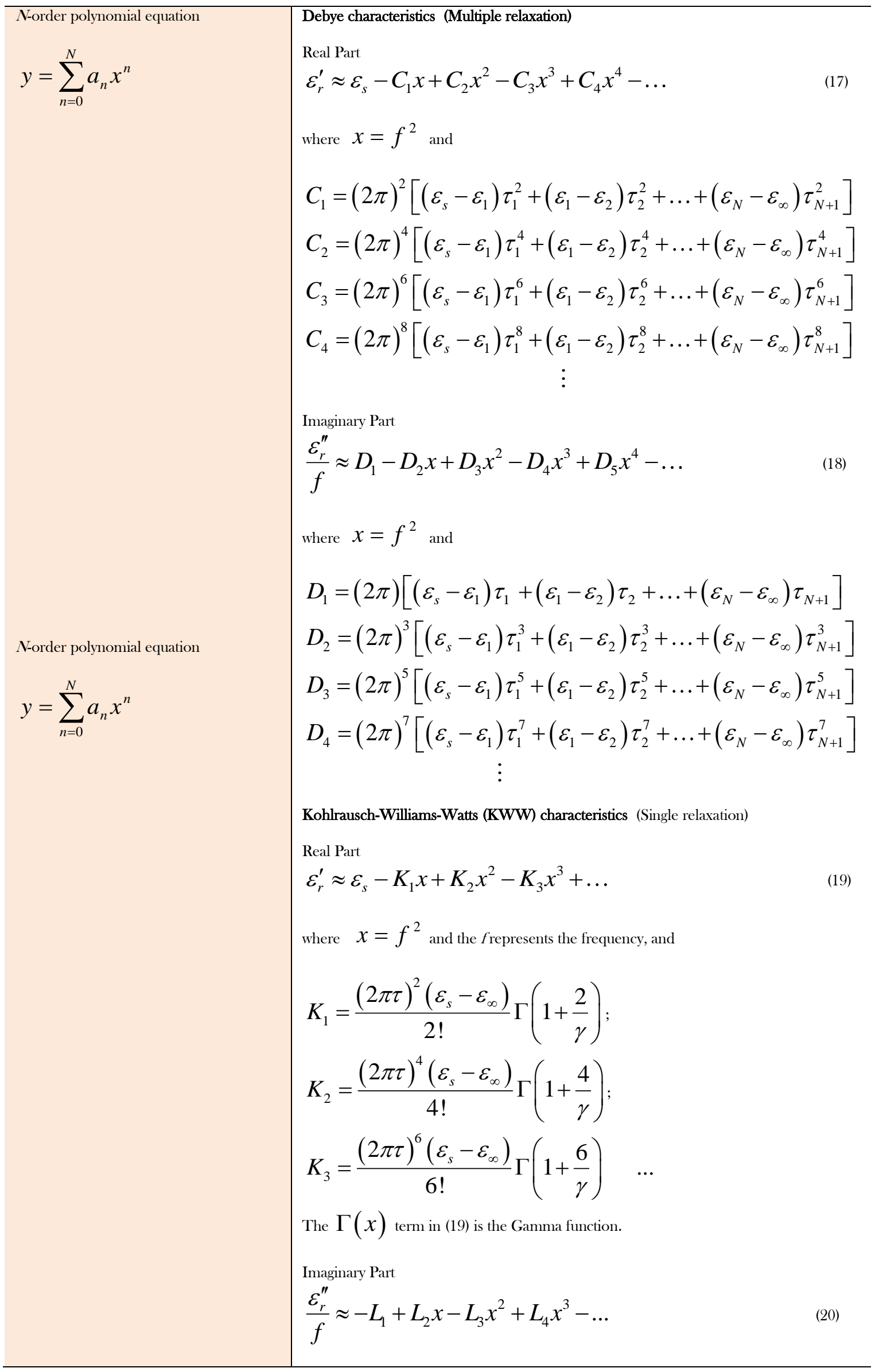




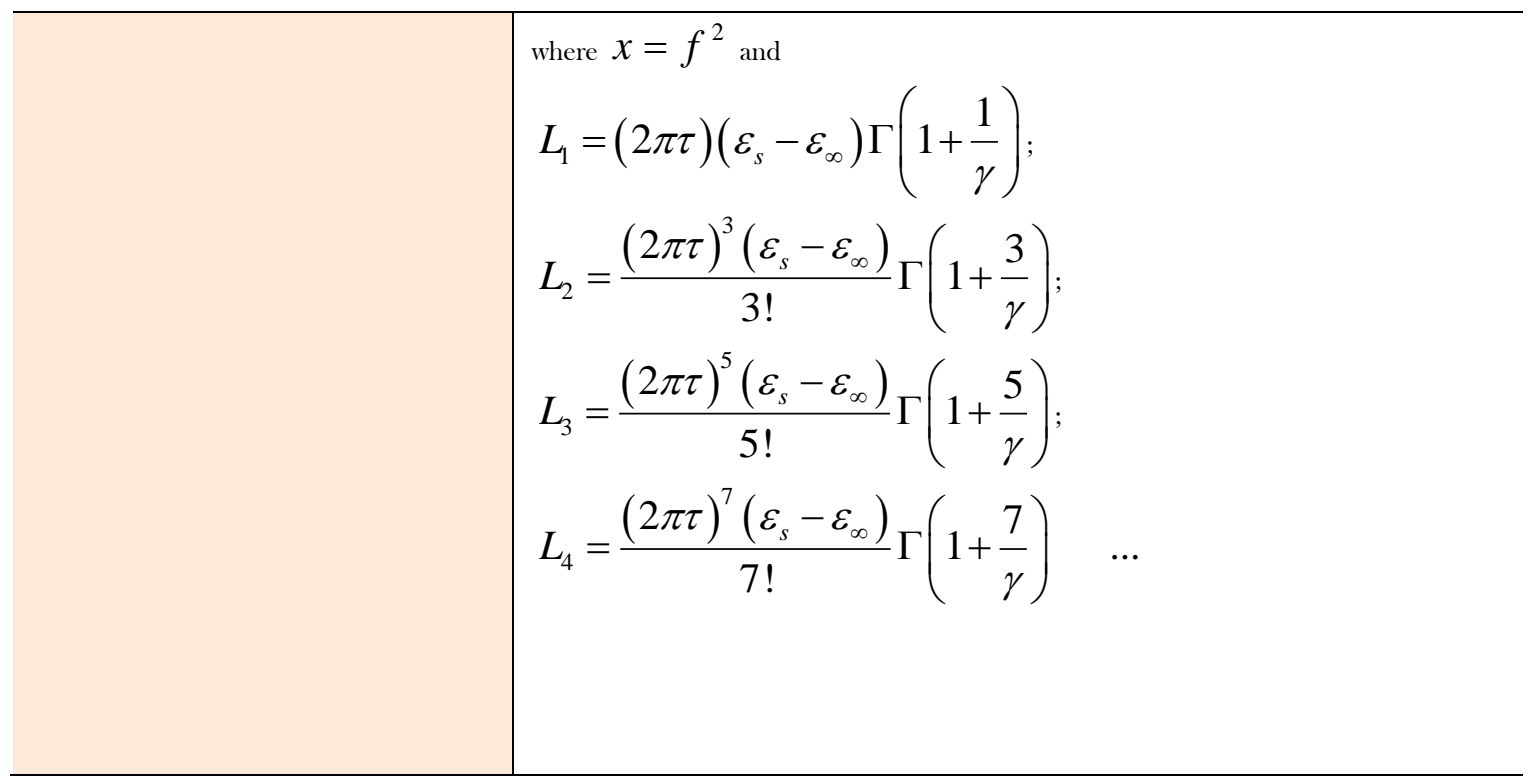

Table 3 The corresponding relationship between the Havriliak-Negami (HN) parameters ( $N, M$, and $\tau_{H N}$ ) and the stretched exponential (KWW) parameters $\left(\gamma\right.$ and $\left.\tau_{K W W}\right)$

The corresponding relationship between the parameters of KWW and HN models in polynomial forms

$$
\begin{aligned}
& \ln \left(\frac{\tau_{H N}}{\tau_{K W W}}\right)=446.62150(\gamma)^{6}-1647.6696(\gamma)^{5}+2426.5867(\gamma)^{4}-1819.4324(\gamma)^{3} \\
& +733.33748(\gamma)^{2}-154.86110(\gamma)+15.423989 \quad \pm 0.38583000 \\
& N=0.66878694(\gamma)^{3}-2.3424665(\gamma)^{2}+2.7111283(\gamma)-0.040639732 \quad \pm 0.072980000 \\
& M=-0.10864371(\gamma)^{3}+0.76452528(\gamma)^{2}-0.0030149013(\gamma)+0.33962219 \quad \pm 0.096463000
\end{aligned}
$$

It is easier to calculate the dielectric properties of materials using the KWW function, since the function has only one unknown parameter $(\gamma)$ compared to the HN function $(M$, $N$, and $\tau_{N H}$ ). Moreover, the relaxation time, $\tau_{K W W}$, is the actual relaxation value of the materials whilst the values of $\tau_{N H}$ are normally adjusted to give the best fit for the experimental data. However, for simplicity, the dielectric properties of materials are usually calculated in the frequency domain.

\subsection{RESULTS AND ANALYSIS}

4.1 Estimation of Parameters $\varepsilon_{s}, \varepsilon_{\infty}$ and $\tau$ Using Linear Equation

The static permittivity, $\varepsilon_{s}$, optical permittivity, $\mathcal{E}_{\infty}$, and relaxation time, $\tau$, can be predicted directly from equations
(10) and (11) based on equation (3). In equation (10), the gradient of the line of the $\varepsilon_{r}^{\prime}-\omega \varepsilon_{r}^{\prime \prime}$ plot is the relaxation time, $\tau$, whilst $\varepsilon_{s}$ can be determined directly at $\omega \varepsilon_{r}^{\prime \prime}=0$. For equation $(6.13 b)$, the inverse relaxation time, $1 / \tau$, can be calculated directly from the gradient of variation in $\varepsilon_{r}^{\prime}$ with $\varepsilon_{r}^{\prime \prime} / \omega$ whilst the intersection between the line and $\varepsilon_{r}^{\prime}$-axis, when $\varepsilon_{r}^{\prime \prime} / \omega=0$, gives the value of $\varepsilon_{\infty}$.

By testing (10) and (11), the measured relaxation time, $\tau$ of bulk water at room temperature, $T$, was found as illustrated in Figure 2 (a), (b) and the result, which includes the estimated values of $\varepsilon_{s}$ and $\varepsilon_{\infty}$ were compared with the literature value as available in Table 4. The results show that the $\varepsilon_{r}^{\prime}$ versus $\omega \varepsilon_{r}^{\prime \prime}$ regression is more stable and reliable than the $\varepsilon_{r}^{\prime}$ versus the 
$\varepsilon_{r}^{\prime \prime} / \omega$ regression estimating the relaxation time, $\tau$, of the materials. Linear plots of $\varepsilon_{r}^{\prime}$ versus $\varepsilon_{r}^{\prime \prime} / \omega$ for water revealed problems with data below $3 \mathrm{GHz}$, thus only data above $3 \mathrm{GHz}$ were used in regression calculation. Meanwhile, the higher frequency measurement $(>20 \mathrm{GHz}$ ) is required for the accurate value estimation of $\varepsilon_{\infty}$ for higher lossy materials ( $\tau \sim 10^{-12}$ ) by using the $\varepsilon_{r}^{\prime}$ versus the $\varepsilon_{r}^{\prime \prime} / \omega$ plot.

The measured relaxation time of bulk water ranging from $25{ }^{\circ} \mathrm{C}$ to $60{ }^{\circ} \mathrm{C}$ obtained from equation (10) is plotted as Arrhenius plots (see Figure 3). The linear relationships in Figure 3 indicate that the temperature dependence of the relaxation time can be described by equation (21).

$$
\ln (\tau)=Q\left(\frac{1}{R(T+273)}\right)+\ln \left(\tau_{o}\right)
$$

Where $R$ is the gas constant $(R=8.3143 \mathrm{~J} / \mathrm{mol} \cdot \mathrm{K})$ and $\tau_{o}$ is a proportionality factor. The slope in Figure 3 represents the mean activation energy, $Q$, of bulk water and give $18.8913 \mathrm{~kJ} / \mathrm{mol}$ compared with the literature value of 18.8 $\mathrm{kJ} / \mathrm{mol}$ [17]. The estimated value of $\ln \left(\tau_{o}\right)$ is -33.1045 or $\tau_{o}=4.1966 \times 10^{-15} \mathrm{~s}$. Obviously, equations (10) and (21) are quite effective to estimate some microwave parameters, particularly for pure Debye relaxation materials.

Table 4 The estimated values of relaxation time, $\tau$, static permittivity, $\mathcal{E}_{s}$ and optical permittivity, $\mathcal{E}_{\infty}$, of bulk water at various temperatures, $T$

\begin{tabular}{|c|c|c|c|c|}
\hline \multirow{2}{*}{$\begin{aligned} \text { Temperature } & (T \\
\pm 1)^{\circ} \mathrm{C} & \end{aligned}$} & \multicolumn{2}{|c|}{ Debye model for water } & \multicolumn{2}{|c|}{ This work } \\
\hline & Thrane, 1976 & al., 1989 & Eq (10) & \\
\hline 25 & $\begin{array}{l}\tau=8.3766 \mathrm{ps} \\
\varepsilon_{s}=78.5198 \\
\varepsilon_{\infty}=4.9\end{array}$ & $\begin{array}{l}\tau=8.28 \pm 0.02 \mathrm{ps} \\
\varepsilon_{s}=78.36 \pm 0.05 \\
\varepsilon_{\infty}=5.4 \pm 0.2\end{array}$ & $\begin{array}{l}\tau=8.3651 \mathrm{ps} \\
\varepsilon_{s}=78.2684\end{array}$ & $\begin{array}{l}\tau=8.6841 \mathrm{ps} \\
\varepsilon_{\infty}=6.9363\end{array}$ \\
\hline 30 & $\begin{array}{l}\tau=7.6118 \mathrm{ps} \\
\varepsilon_{s}=76.6836 \\
\varepsilon_{\infty}=4.9\end{array}$ & $\begin{array}{l}\tau=7.31 \pm 0.05 \mathrm{ps} \\
\varepsilon_{s}=76.56 \pm 0.2 \\
\varepsilon_{\infty}=5.2 \pm 0.3\end{array}$ & $\begin{array}{l}\tau=7.6007 \mathrm{ps} \\
\varepsilon_{s}=76.8199\end{array}$ & $\begin{array}{l}\tau=8.0579 \mathrm{ps} \\
\varepsilon_{\infty}=7.7771\end{array}$ \\
\hline 40 & - & $\begin{array}{l}\tau=5.82 \pm 0.1 \mathrm{ps} \\
\varepsilon_{s}=73.18 \pm 0.2 \\
\varepsilon_{\infty}=4.6 \pm 0.7\end{array}$ & $\begin{array}{l}\tau=6.2485 \mathrm{ps} \\
\varepsilon_{s}=74.0768\end{array}$ & $\begin{array}{l}\tau=6.7760 \mathrm{ps} \\
\varepsilon_{\infty}=7.0199\end{array}$ \\
\hline 50 & - & $\begin{array}{l}\tau=4.75 \pm 0.1 \mathrm{ps} \\
\varepsilon_{s}=69.89 \pm 0.2 \\
\varepsilon_{\infty}=4.0 \pm 0.5\end{array}$ & $\begin{array}{l}\tau=4.7514 \mathrm{ps} \\
\varepsilon_{s}=70.8523\end{array}$ & $\begin{array}{l}\tau=5.7936 \mathrm{ps} \\
\varepsilon_{\infty}=7.9968\end{array}$ \\
\hline 60 & - & $\begin{array}{l}\tau=4.01 \pm 0.1 \mathrm{ps} \\
\varepsilon_{s}=66.70 \pm 0.2 \\
\varepsilon_{\infty}=4.2 \pm 0.5\end{array}$ & $\begin{array}{l}\tau=3.7810 \mathrm{ps} \\
\varepsilon_{s}=68.1510\end{array}$ & $\begin{aligned} \tau & =5.6117 \mathrm{ps} \\
\varepsilon_{\infty} & =12.691\end{aligned}$ \\
\hline
\end{tabular}




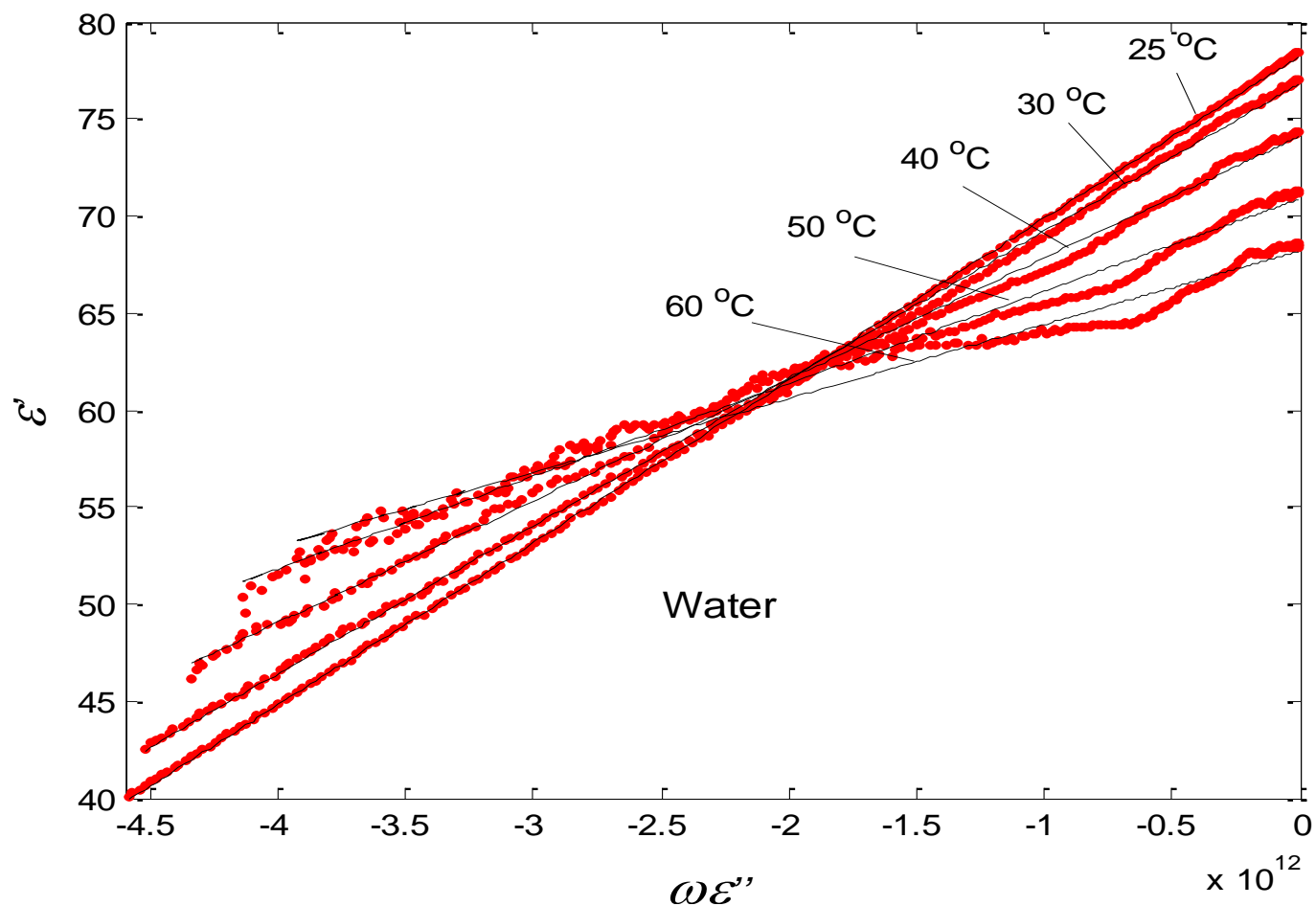

(a)

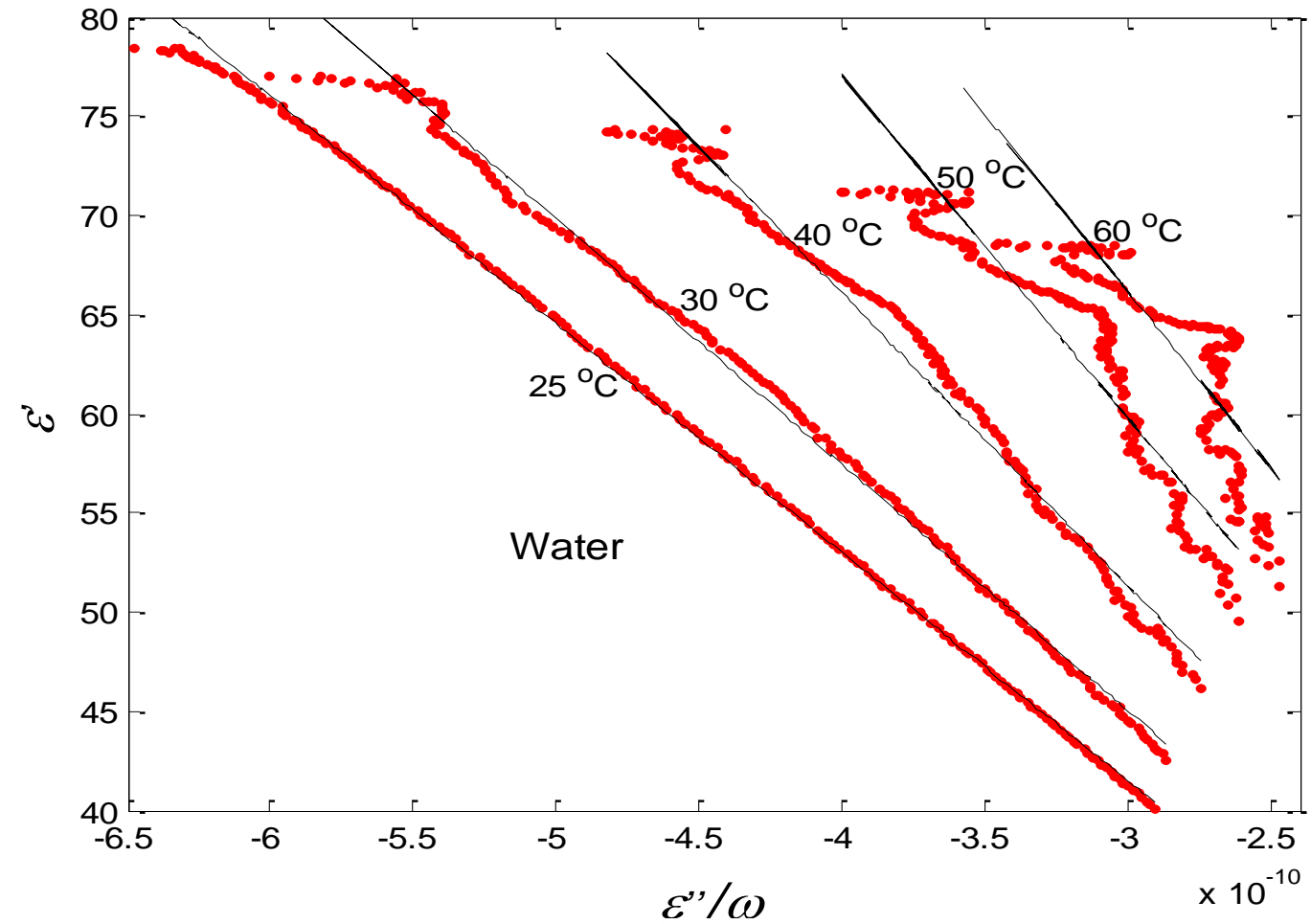

(b)

Figure 2 (a) (b) Variation in $\varepsilon_{r}^{\prime}$ with $\varepsilon_{r}^{\prime \prime}$, which plotting slope represents the relaxation time, $\tau$, of water at $25^{\circ} \mathrm{C}, 30^{\circ} \mathrm{C}, 40^{\circ} \mathrm{C}, 50^{\circ} \mathrm{C}$ and $60{ }^{\circ} \mathrm{C}$ 


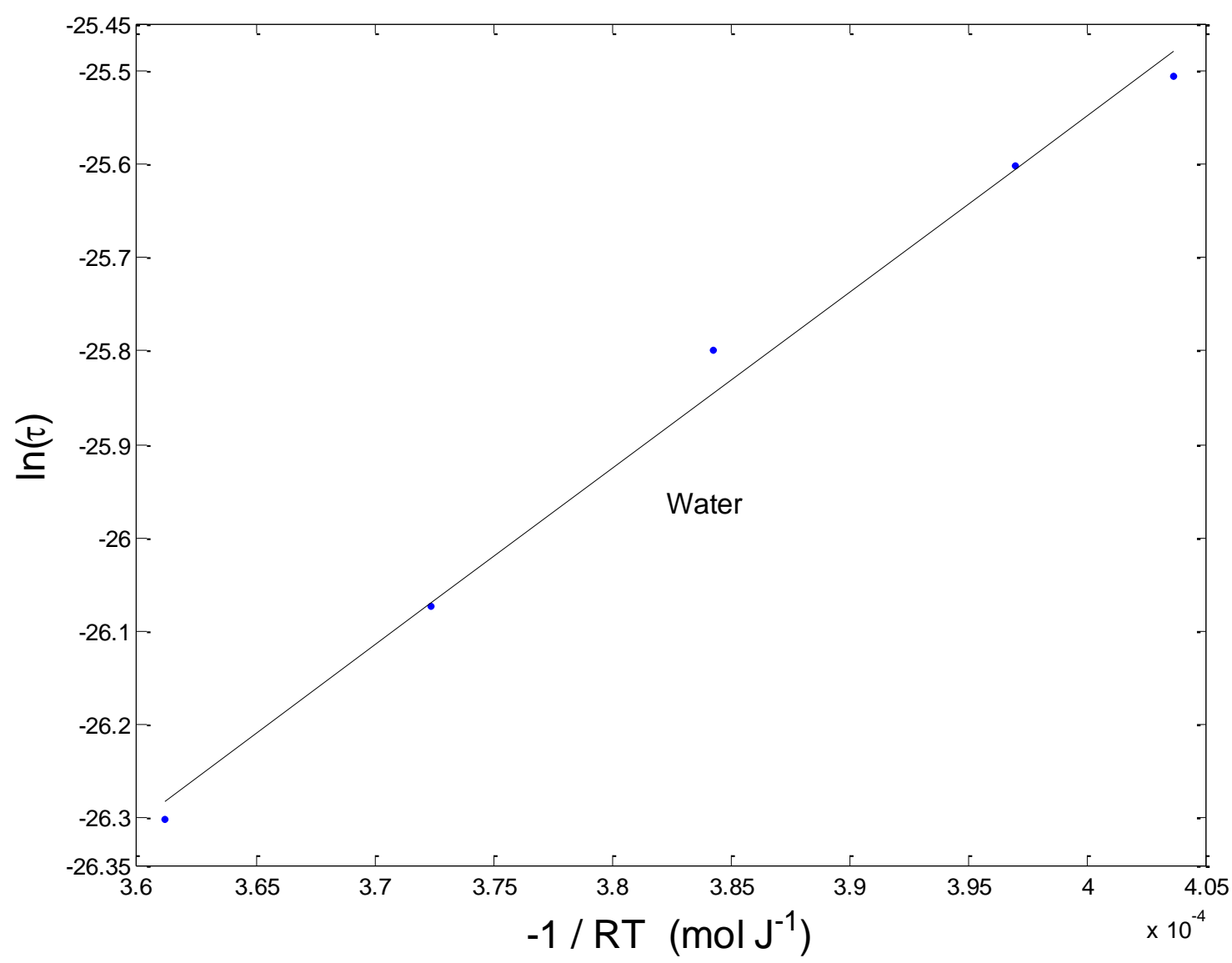

Figure 3 Arrhenius plots for bulk water

\subsection{Estimation of Parameter $\varepsilon_{s}$ Using Higher Order} Polynomial Equation

The higher-order polynomial fitting of Debye models (15) and (16) was applied on pure water. There are 4, 5, and 6 order polynomial fitting that were tested and those polynomial coefficients are compared with the original Debye model [22] at $(25 \pm 1)^{\circ} \mathrm{C}$ as tabulated in Table 5 and plotted in Figure 4. There are no typical rules to determine the order of polynomial to give the best fit with the experimental data. As long as the fitting line is matched with the experimental data, the order of polynomial is considered an appropriate choice. In our experience, the first few terms of coefficients are usually attributed to curve scope at low frequencies, and provide accurate values with mathematical calculation and conversely as shown in Table 5.

In this work, the dielectric constant, $\varepsilon_{r}^{\prime}$ of water as a function of frequency, $f$ and temperature, $T$, was formulated as equation (22) with the aid of equation (15):
By substituting equations (21) and (22) into (10), yields

$$
\varepsilon_{r}^{\prime \prime}=\left[\frac{E q(22)-(-0.291531740265 \times T+85.6619558508)}{2 \pi f \tau_{o} \exp [Q /(R(273+T))]}\right]
$$

where $T$ is the temperature (in ${ }^{\circ} \mathrm{C}$ ) and $\varepsilon_{s}=(-0.291531740265 \times T+85.6619558508)$.

Nevertheless, equations (22) and (23) are only valid for $25^{\circ} \mathrm{C} \leq T \leq 60^{\circ} \mathrm{C}$ and $0.13 \mathrm{GHz} \leq f \leq 20 \mathrm{GHz}$.

The comparison between equations (22) and (23) with measured data is illustrated in Figure 5.

$$
\begin{aligned}
\varepsilon_{r}^{\prime}= & (-0.291531740265 \times T+85.6619558508) \\
& -\left(5.587521507307 \times 10^{-25} T^{3}-4.234240810053 \times 10^{-24} T^{2}-7.041326579374 \times 10^{-21} T+3.67162865847 \times 10^{-19}\right) f^{2} \\
+ & \left(-2.348175849507 \times 10^{-45} T^{3}+5.437541347645 \times 10^{-43} T^{2}-4.191922013075 \times 10^{-41} T+1.160604385157 \times 10^{-39}\right) f^{4} \\
& -\left(-6.503772847655 \times 10^{-66} T^{3}+1.089718588133 \times 10^{-63} T^{2}-6.179833452506 \times 10^{-62} T+1.372700865828 \times 10^{-60}\right) f^{6}
\end{aligned}
$$



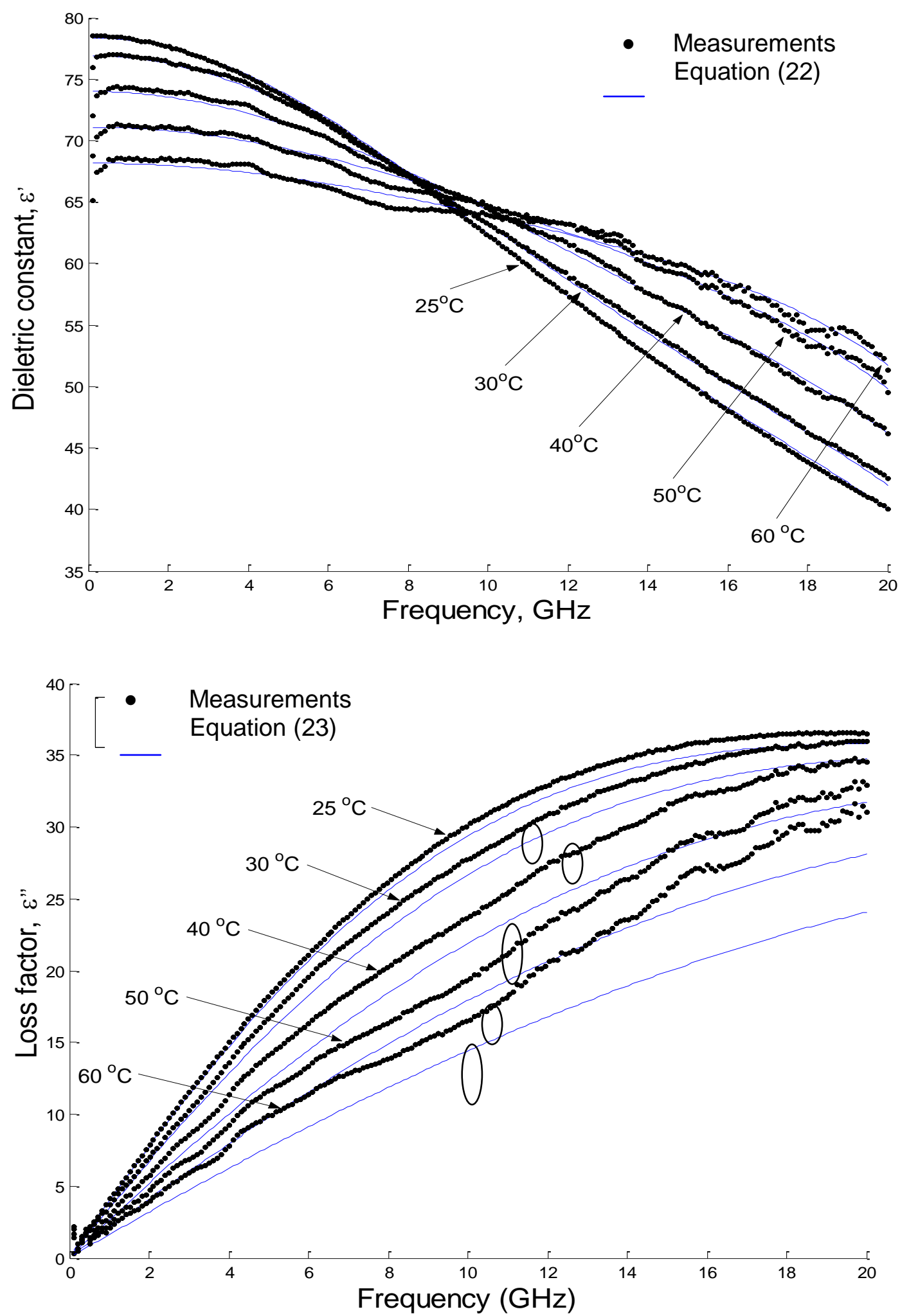

Figure 5 Variation in $\varepsilon_{r}^{\prime}$ and $\varepsilon_{r}^{\prime \prime}$ with frequency for water at $25^{\circ} \mathrm{C}, 30^{\circ} \mathrm{C}, 40^{\circ} \mathrm{C}, 50^{\circ} \mathrm{C}$ and $60^{\circ} \mathrm{C}$ 
Table 5 Comparison between the polynomial fitting approach and the Debye model for water at $(25 \pm 1)^{\circ} \mathrm{C}$

\begin{tabular}{|c|c|c|c|}
\hline \multicolumn{4}{|c|}{ Debye model for water at $(25 \pm 1)^{\circ} \mathrm{C}$} \\
\hline \multirow{2}{*}{$\begin{array}{l}\text { Literature (Thrane, 1976) } \\
\varepsilon_{\infty}=4.9 ; \sigma=0 \\
\tau=8.3766 \times 10^{-12} \\
\Delta=\left(\varepsilon_{s}-\varepsilon_{\infty}\right)\end{array}$} & \multicolumn{3}{|c|}{ This work } \\
\hline & $\begin{array}{c}\text { Coefficients of } \mathbf{4} \text { order polynomial } \\
\text { fitting }\end{array}$ & $\begin{array}{c}\text { Coefficients of } \mathbf{5} \text { order polynomial } \\
\text { fitting }\end{array}$ & $\begin{array}{c}\text { Coefficients of } \mathbf{6} \text { order polynomial } \\
\text { fitting }\end{array}$ \\
\hline $\begin{array}{l}\varepsilon_{s}=78.5198 \\
(2 \pi)^{2} \Delta(\tau)^{2}=2.0393 \times 10^{-19} \\
(2 \pi)^{4} \Delta(\tau)^{4}=5.6492 \times 10^{-40} \\
(2 \pi)^{6} \Delta(\tau)^{6}=1.5649 \times 10^{-60} \\
(2 \pi)^{8} \Delta(\tau)^{8}=4.3349 \times 10^{-81} \\
(2 \pi)^{10} \Delta(\tau)^{10}=1.2008 \times 10^{-101} \\
(2 \pi)^{12} \Delta(\tau)^{12}=3.3263 \times 10^{-122}\end{array}$ & $\begin{array}{c}\varepsilon_{s}=78.4222 \\
A_{1}=2.09533 \times 10^{-19} \\
A_{2}=5.81889 \times 10^{-40} \\
A_{3}=1.13358 \times 10^{-60} \\
A_{4}=9.78302 \times 10^{-82}\end{array}$ & $\begin{array}{c}\varepsilon_{s}=78.4714 \\
A_{1}=2.16143 \times 10^{-19} \\
A_{2}=7.23914 \times 10^{-40} \\
A_{3}=2.19206 \times 10^{-60} \\
A_{4}=4.17349 \times 10^{-81} \\
A_{5}=3.35478 \times 10^{-102}\end{array}$ & $\begin{array}{c}\varepsilon_{s}=78.4756 \\
A_{1}=2.18826 \times 10^{-19} \\
A_{2}=8.25943 \times 10^{-40} \\
A_{3}=3.39696 \times 10^{-60} \\
A_{4}=1.04033 \times 10^{-80} \\
A_{5}=1.79994 \times 10^{-101} \\
A_{6}=1.28057 \times 10^{-122}\end{array}$ \\
\hline $\begin{array}{l}(2 \pi) \Delta(\tau)=3.8747 \times 10^{-9} \\
(2 \pi)^{3} \Delta(\tau)^{3}=1.0733 \times 10^{-29} \\
(2 \pi)^{5} \Delta(\tau)^{5}=2.9733 \times 10^{-50} \\
(2 \pi)^{7} \Delta(\tau)^{7}=8.2362 \times 10^{-71} \\
(2 \pi)^{9} \Delta(\tau)^{9}=2.2815 \times 10^{-91} \\
(2 \pi)^{11} \Delta(\tau)^{11}=6.3200 \times 10^{-112} \\
(2 \pi)^{13} \Delta(\tau)^{13}=1.7507 \times 10^{-132}\end{array}$ & $\begin{array}{l}B_{1}=3.92047 \times 10^{-9} \\
B_{2}=1.20988 \times 10^{-29} \\
B_{3}=3.62133 \times 10^{-50} \\
B_{4}=7.25554 \times 10^{-71} \\
B_{5}=6.25084 \times 10^{-92}\end{array}$ & $\begin{array}{l}B_{1}=3.92160 \times 10^{-9} \\
B_{2}=1.22504 \times 10^{-29} \\
B_{3}=3.94714 \times 10^{-50} \\
B_{4}=9.68369 \times 10^{-71} \\
B_{5}=1.35806 \times 10^{-91} \\
B_{6}=7.69585 \times 10^{-113}\end{array}$ & $\begin{array}{l}B_{1}=4.05296 \times 10^{-9} \\
B_{2}=2.22363 \times 10^{-29} \\
B_{3}=2.47755 \times 10^{-49} \\
B_{4}=1.94559 \times 10^{-69} \\
B_{5}=8.07950 \times 10^{-90} \\
B_{6}=1.64109 \times 10^{-110} \\
B_{7}=1.28868 \times 10^{-131}\end{array}$ \\
\hline
\end{tabular}

4.3 Estimation of Parameters $\varepsilon_{s}, \varepsilon_{\infty}$, and $\alpha$ Using Second Order Polynomial Equation

It is hard to determine the value of parameter, $\varepsilon_{\infty}$, especially for lower and multiple relaxation time materials. For lower single relaxation time materials, like water, this problem can be solved by using a greater measured data range or measuring the material at a sufficiently higher frequency. The size of the data range can be considered based on the uniformity distribution of measured data and parabola shape in the Cole-Cole plots $\left(\varepsilon_{r}^{\prime \prime}\right.$ versus $\varepsilon_{r}^{\prime}$ ) as shown in Figure 6.

Equation (12) is an ideal concept, but in actual experiments, some molecules have much broader dispersion lines and their absorption maxima are distinctly below the ideal concept. In this case, the Cole-Cole characteristics [Equation (13)] are suggested. Obviously, the measured data of $\varepsilon_{r}^{\prime \prime}$ as a function of $\varepsilon_{r}^{\prime}$ can be easily expressed by the second order of polynomial equation. This approach was applied on four standards of lossy liquids, propan-1-ol, ethanol, methanol and water. The quadratic fitting expression, based on measured data for each liquid is tabulated in Table 6.
Besides that, the Debye parameters can be found from the root values of equations (12) or (13). The maximum root value of equations (12) or (13) is represented as $\varepsilon_{s}$, while the minimum value is assumed as $\varepsilon_{\infty}$. The empirical constant, $\alpha$ of the ColeCole model can also be estimated using (13) by comparing the calculated coefficient $\left(P_{1}, P_{2}\right.$ and $\left.P_{3}\right)$ with corresponding fitting coefficient ( $a_{1}, a_{2}$ and $a_{3}$ ) as shown in Table 8. The fitting coefficients values $\left(a_{1}, a_{2}\right.$ and $\left.a_{3}\right)$ in Tables 6 and 7 were compared with the calculated values using (14a), (14b), and $(14 \mathrm{c})$, where the constant parameters $\left(\varepsilon_{s}\right.$ and $\left.\varepsilon_{\infty}\right)$ in those equations were obtained from the literature as listed in Table 7. The more complete the parabola shape in the Cole-Cole plots, the more accuracy there will be in the predicted parameters. The overall comparison results of the Debye's parameters predicted for the four liquids are available in Table 7.

Another important factor in modeling is the uniformity or weight distribution of measured data. From Figure 6, it is evident that a higher weight of data occurs at higher frequency for propan-1-ol and ethanol as well as methanol. For propan-1ol liquid, the measured data of $\varepsilon_{r}^{\prime}$ has a higher density of value between $\sim 4$ to $\sim 5$ for the frequency range $0.13 \mathrm{GHz}$ to $20 \mathrm{GHz}$. 
This condition may influence the tendency of polynomial fitting. In addition, the small variation in $\varepsilon_{r}^{\prime}$ with the greatest frequency range will give a lower sensitivity. The phenomena may provide a large number of relative errors in modeling. Therefore, in this work, the fitting measured data acquired by using formulas (15) and (11) for propan-1-ol and ethanol are $0.13 \mathrm{GHz}-1.5 \mathrm{GHz}$ and $0.13 \mathrm{GHz}-3 \mathrm{GHz}$, respectively. For methanol, the data range $0.13 \mathrm{GHz}-8 \mathrm{GHz}$ was utilized and the results are shown in Table 7.

Table 6 The fitting expressions of $\left(\varepsilon_{r}^{\prime \prime}\right)^{2}$ as a function of $\varepsilon_{r}^{\prime}$ for four standard lossy liquids at $(25 \pm 1)^{\circ} \mathrm{C}$

\begin{tabular}{c|c}
\hline Samples & $\begin{array}{c}\text { Quadratic fitting between } \varepsilon^{\prime \prime} \text { and } \varepsilon^{\prime} \\
\left(\varepsilon_{r}^{\prime \prime}\right)^{2}=-a_{1}\left(\varepsilon_{r}^{\prime}\right)^{2}+a_{2} \varepsilon_{r}^{\prime}-a_{3}\end{array}$ \\
\hline Propan-1-ol & $\left(\varepsilon_{r}^{\prime \prime}\right)^{2}=-0.78294794403552\left(\varepsilon_{r}^{\prime}\right)^{2}+19.752800611883\left(\varepsilon_{r}^{\prime}\right)-60.50581728768$ \\
Methanol & $\left(\varepsilon_{r}^{\prime \prime}\right)^{2}=-0.91140405224695\left(\varepsilon_{r}^{\prime}\right)^{2}+26.637788111836\left(\varepsilon_{r}^{\prime}\right)-97.000514651388$ \\
Water & $\left(\varepsilon_{r}^{\prime \prime}\right)^{2}=-1.0661317094666\left(\varepsilon_{r}^{\prime}\right)^{2}+42.092128800077\left(\varepsilon_{r}^{\prime}\right)-202.66792634657$ \\
& $\left(\varepsilon_{r}^{\prime \prime}\right)^{2}=-0.95057011678464\left(\varepsilon_{r}^{\prime}\right)^{2}+77.938401661636\left(\varepsilon_{r}^{\prime}\right)-262.09787960974$ \\
\hline
\end{tabular}
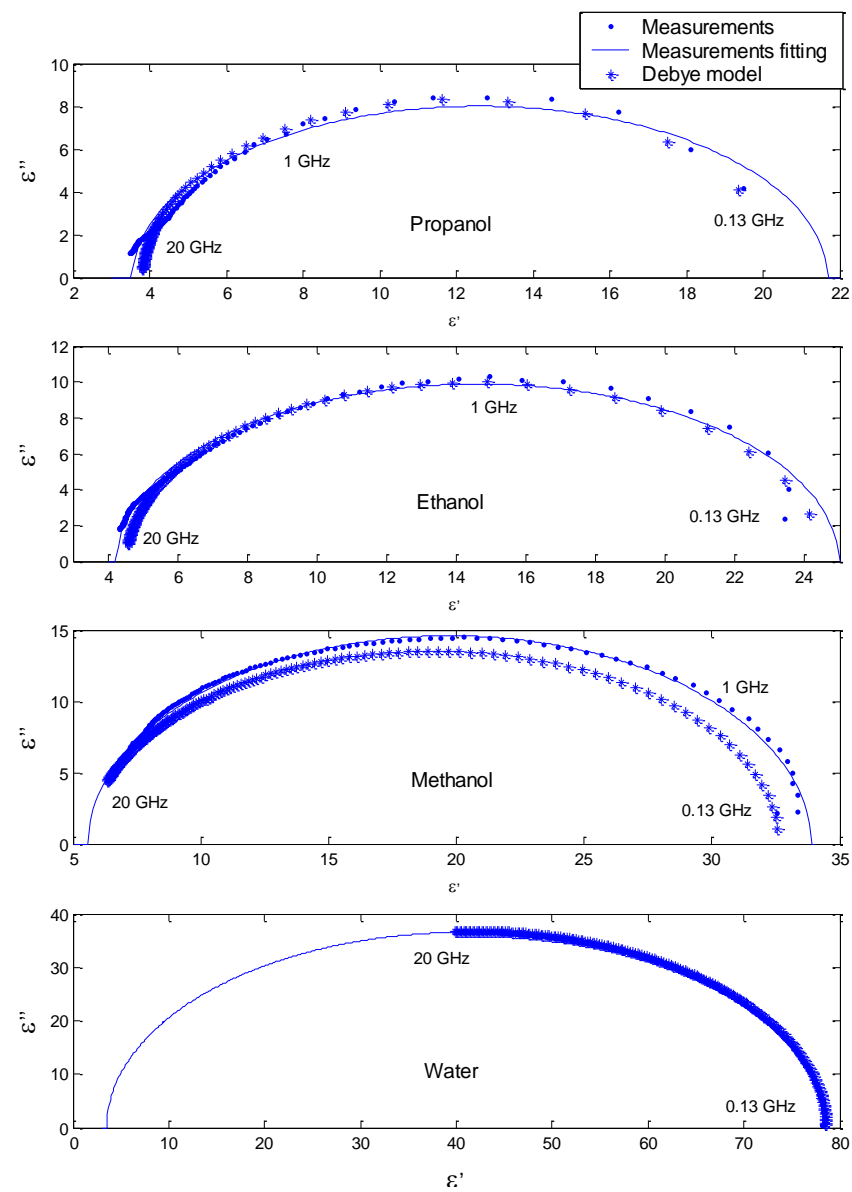

Figure 6 Cole-Cole plots for four standard lossy liquids for a frequency range of $0.13-20 \mathrm{GHz}$ at room temperature $(25 \pm 1)^{\circ} \mathrm{C}$ 
Table 7 The comparison results of predicted Debye's parameters for the four liquids by using various techniques and models

\begin{tabular}{|c|c|c|c|c|c|c|}
\hline Materials & Roots of $2^{\text {nd }}$ order Eq (13) & Fitting & Fitting & \multicolumn{2}{|c|}{ Debye model } & Fitting coefficient \\
\hline Propan-1-ol & $\begin{array}{l}\varepsilon_{s}=21.66109 \\
\varepsilon_{\infty}=3.567664\end{array}$ & $\varepsilon_{s}=20.141$ & $\begin{array}{c}\varepsilon_{s}=20.142 \\
\tau=268.93 \mathrm{ps}\end{array}$ & $\begin{array}{c}\varepsilon_{s}=20.44 \\
\varepsilon_{\infty}=3.8 \\
\tau=320.685 \mathrm{ps} \\
\text { (Grant et al., 1989) }\end{array}$ & $\begin{array}{c}\varepsilon_{s} \varepsilon_{\infty}=77.67 \\
\left(\varepsilon_{s}+\varepsilon_{\infty}\right)=24.24\end{array}$ & $\begin{array}{l}a_{3} / a_{1}=77.28 \\
a_{2} / a_{1}=25.23\end{array}$ \\
\hline Ethanol & $\begin{array}{l}\varepsilon_{s}=24.96384 \\
\varepsilon_{\infty}=4.263356\end{array}$ & $\varepsilon_{s}=24.052$ & $\begin{array}{c}\varepsilon_{s}=24.336 \\
\tau=141.54 \mathrm{ps}\end{array}$ & $\begin{array}{c}\varepsilon_{s}=24.5 \\
\varepsilon_{\infty}=4.52 \\
\tau=165.442 \mathrm{ps} \\
\text { (Grant et al., 1989) }\end{array}$ & $\begin{array}{c}\varepsilon_{s} \varepsilon_{\infty}=110.7 \\
\left(\varepsilon_{s}+\varepsilon_{\infty}\right)=29.02\end{array}$ & $\begin{array}{l}a_{3} / a_{1}=106.4 \\
a_{2} / a_{1}=29.23\end{array}$ \\
\hline Methanol & $\begin{array}{l}\varepsilon_{s}=33.86837 \\
\varepsilon_{\infty}=5.612804\end{array}$ & $\varepsilon_{s}=33.593$ & $\begin{array}{l}\varepsilon_{s}=33.859 \\
\tau=49.091 \mathrm{ps}\end{array}$ & $\begin{array}{c}\varepsilon_{s}=32.616 \\
\varepsilon_{\infty}=5.5849 \\
\tau=47.4451 \mathrm{ps} \\
\text { (Using NBS data) }\end{array}$ & $\begin{array}{c}\varepsilon_{s} \varepsilon_{\infty}=182.2 \\
\left(\varepsilon_{s}+\varepsilon_{\infty}\right)=38.2\end{array}$ & $\begin{array}{l}a_{3} / a_{1}=191.0 \\
a_{2} / a_{1}=39.67\end{array}$ \\
\hline Water & $\begin{array}{l}\varepsilon_{s}=78.47778 \\
\varepsilon_{\infty}=3.513441 \\
\tau=8.3651 \mathrm{ps}\end{array}$ & $\varepsilon_{s}=78.476$ & $\varepsilon_{s}=78.276$ & $\begin{array}{c}\mathcal{E}_{s}=78.5198 \\
\varepsilon_{\infty}=4.9 \\
\tau=8.3766 \mathrm{ps} \\
(\text { Thrane, } 1976)\end{array}$ & $\begin{array}{c}\varepsilon_{s} \varepsilon_{\infty}=384.7 \\
\left(\varepsilon_{s}+\varepsilon_{\infty}\right)=83.42\end{array}$ & $\begin{array}{l}a_{3} / a_{1}=275.7 \\
a_{2} / a_{1}=81.99\end{array}$ \\
\hline
\end{tabular}


Table 8 The estimated empirical constant, $\alpha$ of the Cole-Cole model using (13) by comparing the calculated coefficient ( $P_{1}, P_{2}$ and $\left.P_{3}\right)$ with the corresponding fitting coefficient $\left(a_{1}, a_{2}\right.$ and $a_{3}$ )

\begin{tabular}{|c|c|c|c|c|}
\hline \multirow[t]{2}{*}{ Materials } & \multirow{2}{*}{$\begin{array}{l}\text { Estimated } \\
\text { values of } \\
\qquad \alpha\end{array}$} & \multicolumn{2}{|c|}{ Calculated values of Coefficients in Equation (13) } & \multirow{2}{*}{$\begin{array}{l}\text { Fitting values of } \\
\text { Coefficients } \\
\text { (in Table 7) }\end{array}$} \\
\hline & & $\begin{array}{l}\text { Using } \varepsilon_{\infty} \text { and } \varepsilon_{s} \\
\text { from literatures } \\
(\text { in Table 7) }\end{array}$ & $\begin{array}{l}\text { Using } \varepsilon_{\infty} \text { and } \varepsilon_{s} \text { from } \\
\text { roots of } \text { Eq (13) } \quad \text { ( in } \\
\text { Table 7) }\end{array}$ & \\
\hline Propan-1-ol & 0.912 & $\begin{array}{c}P_{1}=0.7823 \\
-P_{2}+P_{3}=-77.67\end{array}$ & $\begin{array}{c}P_{1}=0.7823 \\
-P_{2}+P_{3}=-77.28\end{array}$ & $\begin{array}{c}a_{1}=0.7830 \\
a_{3} / a_{1}=-77.28\end{array}$ \\
\hline Ethanol & 0.969 & $\begin{array}{c}P_{1}=0.9112 \\
-P_{2}+P_{3}=-110.74\end{array}$ & $\begin{array}{c}P_{1}=0.9112 \\
-P_{2}+P_{3}=-106.43\end{array}$ & $\begin{array}{c}a_{1}=0.9114 \\
a_{3} / a_{1}=-106.4\end{array}$ \\
\hline Methanol & 1 & $\begin{array}{c}P_{1}=1 \\
-P_{2}+P_{3}=-182.16\end{array}$ & $\begin{array}{c}P_{1}=1 \\
-P_{2}+P_{3}=-190.10\end{array}$ & $\begin{array}{c}a_{1}=1.0611 \\
a_{3} / a_{1}=-191.0\end{array}$ \\
\hline
\end{tabular}

\subsection{CONCLUSION}

The approximated series of the dielectric model provides more degrees of freedom to specify the broadness of experimental relaxation peaks. The polynomial approach is implemented to reduce the difficulty of finding out the dielectric's parameters. In this paper, a polynomial fitting was used to estimate the Debye or Cole-Cole parameters. In this work, four types of methods were suggested:

a) Using an $N$-order polynomial fitting, equation (15) was use to estimate the value of $\varepsilon_{s}$. This procedure is applied particularly on the multiple dispersion lossy materials.

b) Applying the linear polynomial fitting of equation (10) to estimate the values of $\varepsilon_{s}$ and $\tau$. This method can be used for both single and multiple dispersion lossy materials.

c) Rooting the second order polynomial fitting of equations (12) and (13) to estimate values of $\varepsilon_{s}$ and $\varepsilon_{\infty}$, as well as determine the empirical constant, $N$ from the coefficients of (13). The techniques are quite accurate for single dispersion lossy materials with non-Debye characterization.

d) Determining the values of $\varepsilon_{s}$ and $\varepsilon_{\infty}$ from the coefficients of second order polynomial equation (13). This rule is only effective for single dispersion lossy materials with pure or approximated pure Debye characterization.

e) The corresponding values of empirical parameters between the Kohlrausch-Williams-Watts (KWW) and HavriliakNegami (HN) functions were re-expressed in polynomial form.
Acknowledgement

This study was supported by the Research University Grant (GUP) from Universiti Teknologi Malaysia (UTM) under project number Q.J130000.7123.02J43.

\section{References}

[1] Alvarez, F., Alegria A., and Colmenero, J. 1991. Relationship between the time-domain Kohlrausch-Williams-Watts and frequency-domain and Havriliak-Negami relaxation functions. Physical Review B. 44: 7306-7312.

[2] Chelkowski, A. 1980. Dielectric physics. New York: Elsevier scientific publishing company.

[3] Coelho, R. 1979. Physics of dielectrics for the engineer. New York: Elsevier scientific publishing company.

[4] Cole, R. H. 1955. On the analysis of dielectric relaxation measurements. J. Chem. Phy. 23: 493-499.

[5] Davidson, D. W. and Cole, R.H. 1951. Dielectric relaxation in Glycerol, Propylene Glycol and n-Propanol. J. Chem. Phys. 19: 1484 1490 .

[6] Debye, P. 1945. Polar Molecules. New York: Dover.

[7] Grant, J. P., Clarke, R. N., Symm, G. T., and Spyrou, N. M. 1989. A critical study of the open-ended coaxial line sensor technique for RF and microwave complex permittivity measurements. J. Phys. E: Sci. Instrum. 22: 757-770.

[8] Hasted, J. 1973. Aqueous dielectrics. London: Chapman \& Hall.

[9] Havriliak, S., and Negami, S. 1966. A complex plane analysis of $\alpha$ dispersions in some polymer system. Journal of Polymer Science, Part C. 14: 99-103.

[10] Jonscher, A. K. 1983. Dielectric relaxation in solids. London: Chelsea Dielectrics Press.

[11] Jordan, B. P., Sheppard, R. J., and Szwarnowski, S. 1978. The dielectric properties of formamide, ethanediol and methanol. J. Phys. D: Appl. Phys. 11: 695-702.

[12] Kraszewski, A., Kulinski, S., Matuzewski, M. 1976. Dielectric properties and a model of biphase water suspension at $9.45 \mathrm{GHz} . J$. Appl. Phys. 47(4): 1275-1277.

[13] Kuang, W., and Nelson, S. O. 1997. Dielectric relaxation characteristics of fresh fruits and vegetables from 3 to $20 \mathrm{GHz}$. J. Microwave Power. 32(2):114-122.

[14] Kaatze U. 1989. Complex permittivity of water as a function of frequency and temperature. J. Chem. Eng. Data. 34: 371-374. 
[15] Mironov, V. L., Dobson, M. C., Kaupp, V. H., Komarov, S. A., and Kleshchenko, V. N. 2004. Generalized refractive mixing dielectric model for moist soils. IEEE Transactions on Geoscience and Remote Sensing. 42(4): 773-785.

[16] Mudgett, R. E., Goldblith, S. A., Wang, D. I. C., and Westphal, W. B. 1977. Prediction of dielectric properties in solid foods of high moisture content at ultrahigh and microwave frequencies. J. Food. Proc. Pres: 119-151.

[17] Nyfors, E., and Vainikainen, P. 1989. Industrial microwave sensors Norwood, MA. Artech House, Inc.

[18] Nyshadham, A., Sibbald, C. L., and Stuchly, S. S. 1992. Permittivity measurements using open-ended sensors and reference liquid calibration - An uncertainty analysis. IEEE Trans. Microwave Theory Tech. 40: 305-314.
[19] Robert, P. 1988. Electric and magnetic properties of materials. Norwood: Artech House.

[20] Prion, A. 1992. Dielectric properties of heterogeneous materials. PIER New York: Elsevier. 6: 40.

[21] Thuery, J. 1992. Microwaves: industrial, scientific, and medical applications. Norwood, MA: Artech House.

[22] Thrane, L., Jacobsen, R., Uhd Jepsen, P. \& Keiding, S. 1995. THz reflection spectroscopy of liquid water. Chemical Physics Letters. 240: 330-333.

[23] You, K. Y., Abbas, Z., Kaida, K. and Mohamad Zaki, A. R. 2010. Improved dielectric model for polyvinyl alcohol-water hydrogel at microwave frequencies. American Journal of Applied Sciences. 7: 270-276. 